\title{
Trocas e reconfigurações religiosas no Baixo Congo: poder e morte entre chineses e bacongos**
}

\author{
Exchanges and religion reconfiguration at Lower Congo: \\ power and death among chinese and Bakongo
}

\section{RESUMO}

Este artigo apresenta reflexões acerca dos recentes contatos religiosos entre chineses no Baixo Congo e membros de uma modalidade de "sociedade secreta" entre os Maniangas. O texto está pautado em uma etnografia que inclui relatos e histórias orais, inclusive dos Bacongos imigrantes em Lisboa (Portugal). Como num caderno de campo, teço considerações a respeito dos relatos sobre reavivamento de mortos, tráfico de órgãos e uma possivel reconfiguração religiosa a partir destes encontros, em um diálogo constante com a literatura pertinente. O texto aporta uma nova forma de vislumbrar as relações sino-africanas, para além da perspectiva estritamente econômica.

Palavras-chave: Baixo Congo - Reconfigurações religiosas - Reavivamento de mortos - Tráfico de órgãos - Relações sino-africanas

\begin{abstract}
This text presents some reflections on the recent religious contacts between Chinese in the Lower Congo and members of a sort of "secret society" among Manianga people, based on a kind of ethnography that includes many reports and oral histories, including the Bacongos immigrants in Lisbon (Portugal). As a field notebook, I construct considerations about the reports of "revival of the dead", organ trafficking and a possible religious reconfiguration from these meetings, in a constant dialogue with the relevant literature. The text provides a new way of looking at Sino-African relations, beyond the strictly economic perspective.
\end{abstract}

Keywords: Bottom Congo - Religious reconfigurations - revival of dead - organ trafficking - sino-African Relations

* Pós-Doutora em Antropologia pelo Centro em Rede de Investigação em Antropologia, da Fundação para a Ciência e a Tecnologia (CRIA/FCT), da Universidade Nova de Lisboa, Portugal. Pós Doutora em Antropologia Social pelo Instituto de Ciências Sociais (ICS), da Universidade de Lisboa, Portugal. Doutora em Lingüística Africana pela Universidade de São Paulo (USP), Atua também no Centro de Estudos Internacionais (CEI), ISCTE, Universidade de Lisboa. Brasil. CV: <http://lattes.cnpq.br/6557567870604974>. 


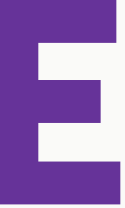

m minha primeira incursão pela floresta do Maiombe, ${ }^{1}$ na zona do Baixo Congo (Bas Congo) da República Democrática do Congo (R.D.C.), interessavam-me os "encantamentos", a agentividade e as relações seculares dos Bacongos ${ }^{2}$ com certas religiosidades praticadas no Brasil e em Cuba. Nomeadamente, o Pajé de Negros, praticado na borda oeste do Estado do Maranhão, e o Palo Monte, religião de matriz banto extensamente praticada em toda a ilha de Cuba. Contudo, algo surpreendente aconteceu ali, em um local em que havia apenascomércio informal, com venda de frutas, legumes e pães, pelas ruelas de terra por onde eu passava.

Havia ali, onde estava na floresta um único comércio de um chinês, que arrumava pacientemente produtos variados: desde bacias plásticas até cornetas. Parecia distante da população local, mas o amigo que me acompanhava, um iombe, disse qualquer coisa ao senhor chinês e ouviu a resposta em lingala (uma das cinco línguas nacionais da R.D.C.). Este acontecimento fez com que meus interesses se voltassem então para as relações entre os bacongos e os chineses, já que alguns dias depois, enquanto passava pelas ruas de Lukula, pequena cidade desta zona em que fiquei hospedada, muitas crianças e adultos mostraram curiosidade (além da esperada nestes contextos) para ver a "mundele" (branca). Como contaram, há mais de 30 anos missionários belgas haviam deixado a área. Desde então, esta geração não havia tido contato com "brancos". Perguntei pelos chineses, já que estavam ali, ainda que em número reduzido. Responderam categoricamente que estes não eram brancos, eram "chineses". Comecei a pensar nas formas possíveis de ver o outro e do outro nos ver, as categorias que se formavam/ressignificavam naquele contexto. Afinal, como os bacongos viam os chineses? E como os chineses viam os bacongos? De que modo e até que ponto os chineses faziam parte ou estavam inseridos na cultura local? Como se daria esta suposta troca de conhecimentos, no nível religioso?

Neste artigo, só me detenho em apontamentos parciais à primeira inquietude e de forma muito direcionada, buscando compreender como os bacongos desta área se relacionam com os chineses, em termos de ontologias aqui nomeadas "religiosas" (Cannell, 2005; Robbins, 2004; Vilaça, 2008), busco traçar alguns apontamentos sobre bruxarias, mortos, tráficos de órgãos, práticas de encantamento e, sobretudo, contatos numa zona específica do Congo.

Interessa, ainda, pensar no modo como a hegemonia cristã dos europeus na África

1 A pesquisa de campo contou com financiamento da FCT (Fundação para a Ciência e a Tecnologia), de Portugal, no âmbito de meu Pós-Doutoramento, enquanto bolsista da instituição.

2 Ainda que a nomenclatura "Bacongo" possa soar pós-colonialista, preferi utiliza-la, pois, meus informantes assim se autodesignaram. Como alguns disseram: "Para uma mundele (estrangeira/branca) ser chamado/ identificada por sua etnia não faz muito sentido, pois os europeus (estrangeiros, em geral) reconhecem apenas a localização geográfica de origem e, em última instância, categorizam todos pelo continente (africanos)". Esta fala significa que o olhar externo categoriza segundo a nação e não pela etnia. Diferentemente de alguns autores (Thornton, 2003, 2013, 2015; Amselle, 2006) que apontam a possibilidade de utilizar simplesmente o termo "kongo" (uma vez que o sufixo - Ba é marca indicativa de coletividade, povo) preferi usar, como indiquei acima, o termo Bacongo (ou sua forma singular, mucongo), já que é/foi assim que meus informantes se apresentaram. Outra indicação importante diz respeito à grafia do nome. Preferi adotar a grafia "aportuguesada", digamos assim, bem como fazer a concordância de gênero e de número, ainda que, conforme referi, o prefixo Ba refira-se à noção de pluralidade nesta língua (quicongo), o que tornaria redundante a marca de plural em português, mas considero que seja sobretudo uma opção política.

3 "Baiombe", povo que habita a zona da floresta Maiombe, falante da língua quiombe, pertence ao grupo étnico dos Bacongos. 
vem sendo transformada, com a presença cada vez mais intensa dos chineses no continente e nesta zona em particular, onde o catolicismo tem sido "ameaçado" por igrejas independentes, invariavelmente pentecostais (De Boeck, 1999; Sarró, 2008; Van Dijk, 2000). Assim, refletir sobre o modo como as ontologias locais se ajustam e se reconfiguram às práticas religiosas chinesas (e vice-versa) passou a integrar minhas inquietudes.

Este texto apresenta uma parte (uma ramificação) de uma pesquisa maior acerca das religiosidades praticadas atualmente pelos bacongos, suas dinâmicas e relações seculares com espaços que conheceram a escravidão (como Brasil e Cuba, dois locais em que desenvolvo pesquisas). Ao mesmo tempo, é também quase um caderno de campo de uma primeira viagem no Baixo Congo, nas cidades de Matadi, Boma e Lukula e que vieram a compor, mais adiante, uma extensa etnografia que venho realizando entre os congoleses imigrantes em Lisboa, desde 2011. Passei a me interessar desde então pela presença dos chineses e seu contato com os bacongos. ${ }^{4}$ Alguns dados são aqui expostos por considera-los interessantes a respeito do significado do "morrer" e da "morte" a partir destes encontros. Uma etnografia mais rica deverá contar com a observação e escuta dos chineses no local, mas como indiquei, por ora, este trabalho restringe-se à visão de uma das partes.

O texto surgiu sobretudo porque, ao longo do período em que estive em Lukula e Matadi (e posteriormente em Lisboa), inúmeras histórias acerca das relações entre os chineses com os mizulas, um tipo de "sociedade secreta" entre os maniangas (Bamanianga), um povo vizinho aos baiombes, foram contadas. As histórias que ouvi envolvemtráfico de orgãos, encantamentos, possibilidades dereviver os mortos e bruxaria. Todas são permeadas pela presença católica, já que muitos informantes afirmaram que tais ensinamentos vieram dos portugueses (muitos afirmaram que integravam ritos católicos). Como os estudos acerca dos

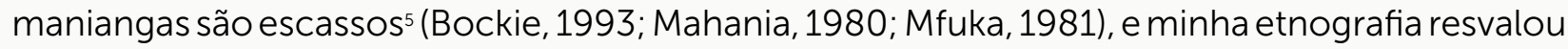
neste povo, por intermédio de meu trabalho com os baiombes, teço alguns apontamentos a partir do vivenciado e, sobretudo, por meio de relatos orais, tanto em Lukula quanto em Lisboa, contados por muitos informantes bacongos. ${ }^{6}$

\section{O Catolicismo português, os mizulas e os chineses}

A presença asiática na África tem sido um dos sintomas de amplo processo econômico, denominado de "o século da Ásia" (Aicarde de Saint Paul, 2004; Ajakaye, 2006; Alden, 2005;

4 Este interesse intensificou-se mais depois de outras pesquisas de campo em Angola (2013), nomeadamente no Libolo (Kwanza Sul), entre os ambundos, no projeto "Libolo" e, posteriormente, em visita a Luanda (2016) quando, pesquisando a igreja Tokoísta, observei que uma família chinesa frequentavao culto dominical do templo do Golfe (bairro em que está situada a igreja).

5 Importante ressaltar que minha etnografianão tinha como foco os Maniangas, mas os Baiombes. Portanto, este textonão apresenta a consistência de dados, como os referidos acima. O que apresento aqui são reflexões acerca de "encontros religiosos" (Young e Gaulet, 1994), antes de mais nada.

6 Considero e trato os bacongos enquanto povo e não nação. Já com os "chineses", uma vez que não consegui dados a respeito de suas origens étnicas, acabei por utilizar o conceito em termos de nação (Oliveira, 1993; Silva, Luz e Helm, 1994) 
Alden e Rothman 2006; Alden e Davies, 2006). Países asiáticos emergentes têm sido focados em termos de sua influência política e econômica. Expressões como "A China em África" têm sido tema recorrente de pesquisas veiculadas em revistas acadêmicas referentes às atividades econômicas e diplomáticas entre os dois continentes.

É, portanto, cada vez mais frequente o número de investigações com temática associada à China na África ou sobre as comunidades de africanos na China. No entanto, enquanto os temas político e econômico têm merecido toda a atenção, as implicações das relações culturais e identitárias sino-africanas (especialmente no que diz respeito às práticas religiosas) têm merecido pouco ou nenhum interesse dos pesquisadores. Este trabalho situase neste contexto, pois objetiva compreender as adaptações e reformulações vinculadas às bruxarias, encantamentos e ao conceito de "morte" quando em situações de encontro. Neste sentido, discussões em torno de "crença" são pertinentes e conduzem à reflexão sobre estas conexões.

Ainda que migrações chinesas para a África ocorram desde pelo menos 500 anos (Xiang e Pieke, 2007), foi a partir do século XIX que se intensificaram. De fato, ficaram mais evidentes a partir da década de 90 do século passado (Ma Mung, 2008; Brautigan, 1998). É também importante mencionar, como apontam Carayannis e Nathaniel, "que as diásporas chinesas mais recentes em África têm sido marcadas basicamente por uma história de "solidariedade" com o 'Terceiro Mundo' durante os anos 50 e 60 bem como por relações econômicas com países do continente" (2011, p. 18) (tradução minha). O Congo e, em especial, o Baixo Congo não constituem um dos destinos preferidos de imigrantes chineses ao longo de décadas (Chang, 1968; Sautman, 2006). No entanto, a presença de japoneses nesta Província é relativamente marcante. Atuaram em diversas áreas, mas basicamente na engenharia e construção naval, no porto de Matadi. Nesta zona, inúmeras "histórias" envolvendo japoneses dotados de alta tecnologia que acabaram por "roubar" energia solar e mineral do Congo são frequentes e muitas vezes associadas à cosmologia local. Entretanto, em relação aos chineses não foi possível levantar números oficiais a respeito de sua presença nesta zona, mas os dados de Sautman (2006) não apontam o Congo (RDC) como um dos dez destinos preferidos pelos chineses na África. De qualquer modo, como estrangeira, impressionou-me não somente a quantidade de chineses nesta área, mas o quanto estavam "embrenhados" em locais inacessíveis e a forma como se "instalaram" nestas sociedades. Portanto, interessa aqui menos uma análise quantitativa, que uma reflexão qualitativa sobre minha etnografia.

Centrei estas reflexões nas migrações recentes de municípios como Matadi, Lukula e Boma, situados no Baixo Congo, complementando meu "quadro qualitativo" de coleta de impressões acerca das relações entre congoleses e chineses, com os imigrantes congoleses/ angolanos (bacongos) residentes em Lisboa. Esta última etnografia forneceu uma base importante para traçar o que nomeio uma "trajetória das percepções" dos bacongos face aos chineses. Ouvi inúmeros relatos, casos e histórias envolvendo a presença de chineses no Congo. Portanto, parte de minha etnografia foi construída a partir de apontamentos da história oral dos imigrantes e de suas memórias. Minha primeira incursão ao Congo tinha como interesse 
principal conhecer a presença católica neste contexto e suas relações com os "ngangas" (líderes/ mestres da medicina tradicional, curadores/mediadores entre os homens e os espíritos). No entanto, a presença asiática` naquela porção do Baixo Congo foi tão marcante que, chegando em Lisboa, comecei a investigar a partir da memória dos imigrantes a relação religiosa entre ambos. Acabei escutando sobre os minzulas/mizulas. Quando perguntava sobre os chineses, eles estavam invariavelmente relacionados aos minzulas e, indiretamente, a negócios ilícitos e a encantamentos e práticas que, por falta de uma palavra apropriada, denomino "mágicas". Os mizulas (com a variante minzula, em alguns casos) seriam uma "sociedade secreta" entre os maniangas - grupo que pertence etnicamente aos bacongos -, povo que se encontra tanto no noroeste de Angola quanto em parte dos dois "Congos" e Cabinda, conformando o que era o antigo "Reino do Congo" (Janzen, 1978, p. xix). A origem do nome, manianga, parece estar relacionada aos movimentos dos chamados "bantos" do norte para o sul (Mulemfo, 1995, p. 340) e é comum a todo o povo que vive às margens (esquerda e direita) do Rio Zaire. As especificações de cada aldeia são dadas pelas preposições adjuntas ao nome como "Manianga ma Luozi"; ou seja, os maniangas que estão próximo do rio Luozi (Ibidem). Interessante ressaltar que este povo carrega um estigma de "desprezados", "amaldiçoados", como aponta Bockie:

Os Maniangas receberam este nome porque se estabeleceram numa área desprezada; Manianga vem do verbo em quicongo nyanga (rejeitar, deprezar). A terra Maninaga foi retratada como uma terra abominável, e as pessoas que decidiram (escolheram) ali se estabelecer são consideradas detestáveis em relação aos demais grupos Kongo: rejeitados por sua "teimosia" em cruzar o Rio Zaire, indo contra os mandamentos dos demais grupos (Bockie, 1993, p. 3, tradução minha).

Conversei com alguns maniangas enquanto estive em Lukula, pequena cidade próxima a Boma e Matadi. Nas conversas, explicavam que entre seu povo a prática de ressuscitar mortos era comum entre os "mizula/minzula", pessoas que tinham/adquiriam este poder por intermédio de ensinamentos que foram transmitidos. Ouvi ainda que somente os "bana bambuta", crianças pertencentes ao clã paterno, numa sociedade matrilinear como a dos Bacongos, tinham o privilégio de entrar em contato direto com seus "batata" (ancestrais, mortos familiares), para receber as instruções acerca da maneira de ressuscitar os mortos, como iria comprovar mais tarde, lendo Zamenga (1985). Explicavam, ainda, que estas práticas foram também ensinadas pelos portugueses que ali estiveram por séculos mais ou menos presentes (Thornton, 1981; Brasio, 1952-1954; Felner, 1933; entre outros). Neste sentido, minha argumentação vai na direção do que Thornton (1998) afirma acerca das "compatibilidades"

7 Não pela quantidade, mas pelo impacto que esta presença causava no local, tanto dos chineses face aos bacongos, como mencionado, mas também no sentido inverso ao observar, tal como iniciei o texto, uma imersão que incluía o aprendizado da língua (o que evidentemente tinha como intuito final a possibilidade do comércio local, por parte dos chineses). 
existentes entre as ontologias do mundo "africano" (especialmente banto) e o cristianismo europeu e sua forma de praticar a religião:

O resultado [dos contatos] foi a emergência de uma nova religião "afro-atlântica" que é via de regra, identificada com o catolicismo, especialmente aquele praticado no "Novo Mundo", um tipo de cristianismo que podia dar conta dos entendimentos religiosos tanto de africanos quanto de europeus (Thornton, 1998, p. 235).

Partilhando esta maneira de conceber os contatos (Young e Gaulet, 1994), temáticas como as conversões, o cristianismo e o catolicismo têm sido objeto de interesse da Antropologia somente a partir do século XX, quando os encontros e seus "resultados", até então ignorados, passaram a integrar a agenda indo além do exotismo, quando afirma que "a limitação daquilo que nós definimos como "comum" faz-nos "cegos", uma vez que somos nós mesmos quem definimos o outro" (Goldman, 2009, p. 112). Assim, tanto um vácuo bibliográfico a este respeito quanto a falta de metodologias e aparatos teóricos mais consistentes fizeram com que não fôssemos capazes, até então, de olhar criticamente para estes processos implícitos de continuidades (Cannell, 2005). No entanto, dou um passo além e afirmo que as "confluências ontológicas" entre centro-africanos e portugueses católicos só foram possíveis por uma manobra adaptativa constante da igreja católica a uma realidade distinta, por um lado. Por outro, a manipulação destas manobras a favor de seus interesses políticos locais, por parte das distintas etnias, agregando assim à discussão fatores políticos além dos previamente arrolados por outros autores - especialmente os próprios missionários em seus relatos de viagens. ${ }^{8}$

Tal confluência parace ter sido o encontro entre os mizulas e os chineses. Mizula/ minzula, palavra do quicongo, língua falada pelo povo bacongo, é o plural do verbo kuzula, que significa "cavar". Mizula significa, por extensão, "escavadores". O termo tem hoje um sentido pejorativo entre os Maniangas, que dizem ter seu uso restrito, e que posteriormente teria se "espalhado" pela zona. Minzulas são, assim, os homens que por encantamentos e técnicas mágicas dominam a prática de "reviver" cadáveres, fazendo-os sair de suas sepulturas sem dispositivos materiais (como a pá ou marreta). Esta parece ser ainda uma prática que só existe na República Democrática do Congo, ainda que, como afirmado acima, a história oral local aponte se tratar de um costume de origem portuguesa: os portugueses teriam iniciardo os bacongos em certos ritos. Vale ressaltar que esta afirmação teve inúmeras variantes, pois alguns informantes (maniangas e iombes) referiam que a prática era dos maniangas, mas desde os primeiros contatos os portugueses travaram conhecimento com estes encantamentos, participando, inclusive, de cerimônias muito secretas entre os mizulas, como informou um iombe.

8 Cf., por exemplo, os relatos de CALTANISSETTA, Luca Da. Relatione della missione. Lisboa: Biblioteca Nacional, 1818 e CAVAZZI, Araldi. Missione evangelica. Vol. A, BK 1. London, 1970 [1665-1668]. 
Estes, diferentemente dos "ladrões de sepultura", pessoas que abrem covas e desenterram mortos apenas com o intuito de se apoderar de algum bem material enterrado com o defunto (dentes de ouro, cordões de ouro ou prata), são pessoas dotadas de poderes mágicos adquiridos por aprendizado (iniciação, ao contrário de dom, como aponta Boyer, 1996), capazes de fazer com que mortos revivam, fazendo-o não aleatoriamente ou por busca de bens materiais (diretos), mas com fins religiosos. Carregam o estigma de "feiticeiros". No entanto, não são jamais confundidos com os "ngangas" (ainda que existam inúmeros tipos de "ngangas", refiro-me aqui ao "nganga nkisi", o "feiticeiro"). De fato, a feitiçaria, tal como é vista pelos minzulas, é uma atividade anti-social por excelência, com uma forte hierarquia da figura do iniciador.

Se, desde o século XVI que a história oficial afirma que os missionários portugueses "converteram" o Nzinga Kuwu (João I) ao Cristianismo, ainda em 1491 (Jadin, 1965; Thornton, 2002), no século XXI são os bacongos que, aliados aos chineses, utilizam-se de práticas de encantamento supostamente trazidas ou aperfeiçoadas pelos portugueses para reelaborações religiosas com fins que perpassam um imaginário local e que se estendem das práticas de bruxarias até o tráfico de órgãos. Assim, uma nova rede social tem sido estabelecida por intermédio de alianças elaboradas entre os bacongos e os chineses (e os portugueses na ancestralidade) criando novas dinâmicas territoriais e espaciais.

Abordo aqui não somente a presença chinesa na região do Baixo Congo, mas (e sobretudo) o desenvolvimento desta presença no imaginário religioso bacongo e suas reelaborações. De fato, o imaginário religioso local está mais vinculado ainda às práticas católicas trazidas pelos portugueses do que propriamente dos chineses, ainda que os informantes tenham referido que certos materiais, como o incenso e, até a imagem de um Buda, tenham sido "vistas" (relatadas) em algumas cerimônias de revivificação dos mortos. Outros relatos deram conta de que ingredientes "chineses", como o "zinzibe" (gengibre), eram agregados a uma conhecida bebida feita pelos minzulas em parceria com os chineses para dar "poder" e "fama" a quem dela bebesse. Assim, as relações e trocas são perceptíveis, tanto no nível material quanto no ontológico, uma vez que envolvem poder e este incorpora símbolos externos na ressignificação à luz da ontologia-religiosidade bacongo, tal como indicam Balandier (1956) e Vansina (2004). Já em relação ao catolicismo, as trocas estão tão imbricadas a ponto de ser difícil pensar num universo bacongo sem esta presença. Dos relatos ouvidos, destaca-se a necessidade de rezar um "Pai Nosso"9 antes da cerimônia de revivicação ainda no cemitério, ou a utilização de terços e imagens de santos.

Uma imagem que penso ser possível aqui para dar conta destas redes de trocas é a metáfora das ramificações (branchement) que prevê, para além da possibilidade única e previsível, como aponta Amselle (2001), as interconexões constantes de uma rede significativa.

9 Estes relatos remeteram-me às minhas experiências em Cuba, com o Palo Monte, religião de matriz centroafricana (banto) extensamente praticada no país, em que as relações com o Cristianismo e a Igreja católica são intrínsecas e variáveis, desde a necesssidade de, para a iniciação (rayar-se), o neófito ser batizado (e devido à grande procura de batismos tardios, já que desde 1959 a ilha é oficialmente "comunista" e portanto laica, uma igreja católica, localizada em Lawton, realiza às quartas feiras um batismo "coletivo"), até a utilização de roupas eclesiais em cerimônias, rezos, etc (somente para citar a parte material dos encontros). 
Assim, ao observar o modo como as alianças entre estes grupos se manifesta, evidencio empoderamentos que ultrapassam as marcas materiais e assumem, segundo Appadurai (2001), uma caracterização não material, que se configura em modos de fazer e operar. Observo estes modos no que concerne à religisiodade, ainda que nem sempre estejam/sejam explícitos ou fáceis de vislumbrar. No caso dos chineses, considero que sua presença nesta parte da África é muito recente e qualquer apontamento seria especulação.

\section{Ndokis, sonhos e chineses}

Na região da África Central, a "bruxaria" (refiro-me aqui às bruxarias dos ndokis, não dos minzulas) é uma prática que ocorre simbolicamente pela ingestão, sobretudo de carne (supostamente humana), o que leva a vítima a mudar seu status quo a partir de então. Esta relação entre a ingestão como transformadora é latente nesta zona a tal ponto que ninguém diz que vai "matar" outra pessoa na/com bruxaria, mas que vai "comer" a alguém (Bukuasa, 1973), o que justifica o termo "Balekisi ye" (comido pelo nkisi). Deste modo, a feitiçaria é quase uma "contaminação": alguém que come algo inofensivo (carne) descobre posteriormente que o ingerido era carne humana, em outra dimensão. Ele se tornou, portanto, um "feiticeiro" (ndoki) sem seu conhecimento/consentimento e, agora, tendo que "pagar" a carne consumida, vê-se obrigado a "matar" (comer) pessoas, quase sempre de seu círculo familiar.

Impulsionados por vingança, ciúme ou ambição, deixam o grupo familiar para participar de um grupo anti-social (o grupo dos ndokis). Levam uma vida dupla: aparentemente, são pessoas inofensivas no "primeiro mundo" (pequenos comerciantes, meninas, velhos, etc), que viajam durante a noite ao que nomeiam de "segundo mundo", um universo paralelo constituído quase sempre por construções suntuosas, carros de luxo e muita fartura. Uma "bruxa" pode ter a aparência de uma menina de 10 anos em sua comunidade, mas no "segundo mundo" pode ser casada, idosa, ou pode se transformar em uma sereia, como Mami Wata, vivendo nas profundezas dos rios. O percurso entre as distintas dimensões do mundo (o mundo de "cá" e o "segundo mundo") explicita uma ontologia singular de apropriação da "realidade". Assim, sonhos e percepções (sobretudo gustativas e olfativas) acabam por se tornar interações simétricas e complementares, pois são partes de uma mesma unidade que interage e redimensiona o que é tido como realidade. Como sugere Carrithers (apud Vitebsky, 1992, p. 8), para melhor compreensão desta interação, dei atenção ao que ele chamou de "narratividade", ou

a compreensão de complexas redes de novas conexões e mudanças de atitudes pelas quais as pessoas percebem [dão-se conta] as ações não apenas como respostas para circunstâncias imediatas ou estados mentais impostos por um interlocutor, ou si próprio, mas como parte de uma história (Carrithers, 1990, p. 269) (tradução minha). 
Tratei de dar ouvidos a estas outras narratividades para compreender situações em que acusações de bruxaria, igrejas pentecostais, catolicismo e tráficos de órgãos faziam parte da mesma história. Os sonhos desempenham relevante papel para o entendimento destas outras "narratividades", fornecendo pistas acerca do imaginário local sobre os chineses, no que concerne à religiosidade. Para os ndokis e também para os mizulas, muitas vezes os sonhos são símbolos passíveis de uma interpretação, cujo significado é oculto ou maior. Podem também ser experiências quase individuais (Csordas, 1997) e não sempre necessitam de um "aval" ou de sua reconstrução pela coletividade. Chamo a atenção para pensar os sonhos como um tipo de experiência, categorizada como cultural, mas não completamente coletiva, já que prescinde de ressignificações e reconstruções sociais para sua legitimidade. Neste contexto, os sonhos são uma experiência do "eu", que transforma e remodela a "pessoa" (self). Como aponta Ewing:

Através deste processo reflexivo, as representações do "eu" tornam-se sinais, como unidades da linguagem ou outras representações culturais como os mitos e as imagens. Sonhos, os quais experienciamos através da linguagem e das imagens, são igualmente feitos de signos (Ewing, 1990, p. 57).

Neste contexto de bruxaria, os sonhos funcionam como uma possibilidade de ingresso em um universo restrito do "segundo mundo". Ali, a pessoa que ingeriu algo e, portanto, ficou "aberta" à bruxaria, submerge num certo mundo em que todas as redes sociais estão formadas. Há reinos, cidades e famílias, inclusive com comércio e muitos bens materiais - e são estes muitas vezes que motivam a bruxaria.

Para os bacongos, a intenção de transformar alguém em ndoki na maioria das vezes tem origem no interior da família. De fato, é quase impossível atacar alguém com quem não se tenha proximidade ou laços familiares e/ou sociais, uma vez que a eficácia da feitiçaria depende do acesso a vestígios materiais do enfeitiçado, como restos de unha, rastros ou cabelos. Como os bacongos são matrilineares, as bruxarias são transmitidas por mulheres (mãe, avó). Ao romper com parte do mundo dos humanos (pois o ndoki vive neste duplo universo), os feiticeiros se caracterizam pela falta de afetividade e, de forma mais ampla, ausência de culpa. Assim, confissões e relatos detalhados de feiticeiros geralmente causam repulsa em quem os escuta, ajudando a alimentar o sentimento de horror contra a "bruxaria". Crianças pequenas, acusadas de bruxaria, contam seus crimes (assassinato dos pais, por exemplo) com detalhes mórbidos e distanciamento emocional dramático (De Boeck, 2000).

Em uma direção diametralmente oposta, os minzulas elegem a bruxaria, o que significa que decidem por este aprendizado - ou então está na sua linhagem (kanda). Assim, a parceria que se estabelece com os chineses, por exemplo, será voluntária e baseada em interesses mútuos. É nesta relação que foquei minha atenção, ainda que os caminhos entre ambos 
(minzulas e "ngangas") algumas vezes se cruzem.

\section{Corpos, bebidas e chineses}

A relação dos chineses com os mizulas acabou por se tornar metonímica, pois ao relacionarmos os Bacongos ou os Maniangas com os chineses de imediato se estabelece uma conexão com o universo da morte e a manipulação de cadáveres. O imaginário local conta com uma definição de espaços: enquanto os mizulas praticam rituais de magia que envolvem corpos, com a finalidade da aquisição de forças espirituais; os chineses trabalham com a manipulação de cadáveres com a finalidade de comércio, ainda que muitos relatos indiquem que esta conjuntura só foi possível graças à força "mágica" dos chineses. Assim, a conjunção entre interesses aparentemente tão distintos acaba por ter um elo de contiguidade: o domínio de forças mágicas. No Congo (aliás, nos dois Congos), até há pouco tempo atrás o negócio ilícito envolvendo cadáveres propiciava pânico em grande parte da população e famílias passaram a abrir mão de seus rituais funerários tradicionais e a usar ácido nítrico nos corpos de seus parentes para acelerar a decomposição da carne e dos ossos. Tal conduta objetivava evitar que estes fossem roubados, vendidos ou transformados pelas mãos dos mizulas e chineses, pois para além do suposto tráfico de órgãos, também poderiam produzir a partir dos ossos dos mortos uma bebida "mágica" com ingredientes especiais que garantiriam uma vida bemsucedida a quem a ingerisse. Tais dados aqui mencionados são relatos de histórias, algumas vezes contadas em primeira pessoa e citadas em referência a casos ocorridos com parentes, amigos - portanto, em terceira pessoa.

As estreitas relações entre mizulas e chineses e os relatos locais (Cunha e Ndungi, 2013) apontam que desde os comerciantes de províncias até grandes políticos e militares fazem uso destas bebidas. Trata-se de um fenômeno que a Justiça e as Forças de Segurança locais encontram dificuldades em combater, pela carência de instrumentos adequados (sistema judiciário baseado nos preceitos ocidentais, que não se ajusta às ontologias locais). Não há legislação que respalde acusações de bruxaria. Por outro lado, somente perícias laboratoriais permitiriam averiguar se houve, de fato, uso de ossos humanos na confecção dessas bebidas. Como não há recursos para tanto, as acusações seguem pela via da informalidade. De certo modo, a ingestão desta bebida "mágica" acaba por se tornar o antagonismo da reação provocada pelos "ndokis". Aqui, ao se ingerir algo (involuntariamente), seu estatuto muda negativamente; enquanto ali, ao se beber algo (voluntariamente), seu estatuto muda positivamente (em termos materiais, pois o que se consegue é dinheiro, fama, etc).

Na região de Lukula dizem que até o ano de 2010 nunca se havia ouvido falar sobre os mizulas. A partir da presença mais intensa dos chineses nesta área rumores a respeito de roubos em cemitérios, uso indevido de ossos para elaboração de bebidas e bruxarias passam a ser 
recorrentes, até que os chefes locais (nganga nfumu) proibiram a entrada de pessoas estranhas nos cemitérios. Quando estive em Lukula em 2011, fui proibida de entrar no cemitério principal da cidade. Para entrar no local em que a irmã de meu amigo iombe estava enterrada, foi preciso recorrer a uma aldeia vizinha, solicitar permissão ao nagnga nfumu (um chefe local). A desconfiança de que iríamos desenterrar os ossos para venda e bruxaria era grande, sobretudo a partir da presença de uma "branca" e "estrangeira". Este episódio fez-me pensar até que pontoos chineses seriam os únicos "parceiros" dos mizulas nesta manipulação dos mortos e se não seria o fato de eu ser estrangeira, mais do que "ser branca", que causaria desconfiança.

O cemitério de Kikanda, em Matadi, havia sido desapropriado anos antes e inúmeras casas foram construídas no local. Neste período, por volta de 2007, os chineses já residiam na cidade e casos de tráficos de ossos foram relatados. Muitas pessoas que construíram suas casas naquele local aproveitaram para vender os ossos encontrados. Ainda hoje é possível ouvir histórias sobre os "ossos de Kikanda" e invariavelmente os chineses figuram entre os protagonistas destas histórias como compradores, provavelmente para fins religiosos, que os informantes não souberam precisar (seria para rituais internos, religiosos, medicinais?). Esta tríplice relação (entre ndokis, mizulas e chineses) parece estar configurada, não apenas por interesses comerciais/econômicos, mas também interesses mágico-religiosos.

Ndokis e minzulas são seres com poderes especiais, capazes de se deslocar no tempo e no espaço, utilizando distintos meios para tanto. Enquanto os ndokis viajam para o "segundo mundo" - local em que as distâncias são percorridas em um instante, pois um ndoki que vive em Matadi pode voar para Bruxelas, buscar um familiar que vive ali e levá-lo a participar, num cemitério congolês, de um banquete cuja vítima vive na Irlanda - em apenas alguns segundos, utilizando cascas de frutas ou pedaços de pau que se transformam em limusine ou avião, os mizulas, por outro lado, não parecem ter o mesmo poder de deslocamento e, de fato, não o necessitam, uma vez que seus "sujeitos" (alvo de bruxaria e manipulação) são outros. Enquanto os ndokis buscam humanos para transformá-los em "mortos-vivos", os mizulas procuram mortos para os reavivarem, dar-lhes vida, ainda que seja uma vida distinta desta terrena, usual. A finalidade desta prática de reavivamento ainda não é clara. Enquanto alguns relatos afirmam se tratar de uma "obrigação" do Kanda (linhagem), outros se referem ao fato de que essas práticas serviriam para aumentar/fortificar os poderes mágicos dos mizulas. De qualquer modo, a presença chinesa, tanto entre ndokis quanto entre mizulas, parece reforçar poderes. Ainda que de formas distintas, trabalhar com um chinês, magicamente, ou estar perto dele, potencializa poderes. Nesta relação, há interesses comerciais por parte dos bacongo/ manianga, mas há também um interesse mágico.

Não tive acesso a nenhum ritual religioso de necromancia realizado pelos mizulas. Ao mesmo tempo, como a bruxaria possui um status de acusação e não de autodefinição (Boyer, 1996), conversei com inúmeras pessoas que, segundo relatos de terceiros, eram "ndokis". Mas nenhum desses informantes se definiu como possuidor tal identidade. Portanto, todas as histórias que apresento dizem respeito a relatos de pessoas que "ouviram falar" sobre determinado assunto. A mesma situação ocorreu em relação aos chineses: nenhum dos 
entrevistados referiu ter relações próximas com algum chinês. Parece que esta proximidade gera forte desconfiança por parte da comunidade no que tange à bruxaria. Portanto, estar próximo a um chinês é, no mundo oculto, religioso, benéfico e positivo. Contudo, para a vida social, trata-se de uma relação envolta em preconceito, que pode produzir fortes indícios para acusações.

Durante esta pesquisa de campo, em Lukula, sofri grande pressão da comunidade de forma velada sem muitas falas. Meu amigo iombe, na casa de quem fiquei hospedada, me acompanhava e foi advertido diversas vezes de que se entrássemos juntos no cemitério da cidade ele seria proibido de voltar para sua terra, pois passaria a figurar como um "mizula" em potencial, por estar acompanhado por uma "branca", que provavelmente poderia ter relações com um chinês (portanto, gente "de fora"). Mas, e por parte dos chineses, seria somente um interesse puramente comercial por trás desta suposta "parceria"? Para além da elaboração da bebida, há ainda o tráfico de órgãos, atribuído aos chineses. Faltam dados etnográficos mais consistentes (especialmente no que diz respeito aos chineses) para elaborar um quadro detalhado desta relação, mas o que pude delinear até este momento é que, segundo o imaginário local, os chineses precisaram se aliar a um grupo de religiosos/manipuladores de corpos desta zona (se aliaram então aos mizula, em princípio, mas atualmente as parcerias tomaram configurações maiores), para ter acesso aos corpos que supostamente iriam manipular com a finalidade do tráfico de órgãos. Não é minha intenção buscar a veracidade destas histórias, acusando um grupo ou outro seja de feitiçaria, seja de tráfico de órgãos. Interessa aqui somente compreender de que modo são efetuadas as alianças entre os distintos grupos e como o imaginário local dos Bacongos se apropria de práticas externas para reelaborar sua religiosidade. Desde a entrada do Cristianismo nesta zona tem sido assim, há séculos (Jadin, 1968; Thornton, 2002; Saavedra e Straus, 2009).

Os mizulas parecem ter como benefício desta relação não apenas o aporte financeiro (fundamental neste contexto de África), mas a aquisição de certos "poderes mágicos" que viriam de duas formas: por aprendizado (e então os chineses estariam trocando informações "mágicas" e instruindo, formando um grupo de religiosos Bacongos) ou pelo que denomino "simbiose" (na ausência de um nome que dê conta desta realidade), que seria a aquisição de "poderes mágicos" ou "aumento de força mágica" pelo simples fato de estarem próximos dos chineses, já que estes são considerados "um povo superior", "um povo mágico", "feiticeiros", "donos do verdadeiro conhecimento das bruxarias". Por outro lado, a prática de reviver mortos, própria dos mizulas, foi adquirida em sua origem pelo contato com os portugueses, tendo como pano de fundo o catolicismo português.

\section{Considerações finais}

Neste artigo foram abordados os encontros religiosos e as práticas rituais, sob uma 
perspectiva plural, não apenas com base em uma etnografia, como na memória e em relatos orais de muitos imigrantes bacongos em Portugal, ativando o que Commaroff e Commaroff (1992, p. 27) chamaram de "historicidade endógena", numa tentativa de aproximação/complementação entre etnografia e história, cuja intenção era uma reflexão sobre um fenômeno recente de encontros religiosos num espaço específico da África Central. As relações entre estes dois povos e os interesses envolvidos numa prática de reavivamento de mortos são instigantes. Neste cenário, também são inspiradoras as histórias pregressas de contato religioso, tanto por parte dos bacongos com o catolicismo português quanto o contrátrio, quando portugueses ali presentes participavam/partilhavam deste universo dos minzula, por intermédio dos ensinamentos de certas práticas, da transmissão de conhecimentos e participação ativa na sociedade secreta. Os chineses, que entraram recentemente nesta história ${ }^{10}$ de mais de cinco séculos de contatos, já mostram, entretanto, ligações importantes e interessantes com os bacongos. Relações que se configuram ao longo do tempo e dos interesses de ambos lados. Afinal, a questão das identidades e a da dita "cultura" em nações/espaços que experimentaram os encontros coloniais têm sido examinadas por autores de distintas orientações teóricas, desde Franz Fanon (1967), Léopold Senghor (1977) e, mais recentemente, por estudos como os de Bhabha (1994), Appadurai (1986) ou Mboukou (1981).

A África, especialmente a África Central, com uma longa e rica história de contatos com Portugal, parece ser um dos locais em que a "cultura híbrida", proposta por Bhabha (1994) é evidenciada, não apenas pelo aspecto geográfico, mas por dar lugar àquilo que Appadurai (2001) conceituaria como "comunidades imaginadas". Estas comunidades alargamse, evidentemente, a tantas outras possibilidades por meio de encontros. Esta pequena parte de uma pesquisa maior, envolvendo o catolicismo e as práticas locais, se distingue de outros trabalhos que abordam estas relações culturais entre sino-africanos por não se restringir ao aspecto econômico, ampliando a perspectiva sobre os encontros, o conhecido "sincretismo" e os debates sobre estes temas. Busquei compreender novos fenômenos que surgem em contextos diversos, das diferenças, que questionam e reativam determinados conceitos, como "heranças" e "inovação".

Pluralizando o entendimento banal de sincretismo e contato - definidos geralmente como fusão, combinação, associação de diferentes sistemas de pensamentos e práticas busquei explorar os múltiplos caminhos pelos quais as relações e associações são forjadas, entre diferentes aspectos de experiências culturais. O desafio também é metodológico e teórico, na medida em que impõe a árdua tarefa de produzirmos "sincreticamente". Ouvir múltiplas vozes consiste em um dos caminhos necessários a se percorrer para melhor compreensão, repensando fronteiras e ontologias.

10 Interessante observar a realidade cubana acerca da presença chinesa na ilha, pois de certa forma possui dados semelhantes, no que concerne à religiosidade. Atualmente os chineses estão muito arraigados na ontologia religiosa local que dentro do Espiritismo cubano ou mesmo do Palo Monte (religião de matriz banto extensamente praticada na ilha com inúmeras variantes) a presença de "espíritos chinos" ou "com tendência china" (como dizem os cubanos) são frequentes. Neste aspecto ver Hewitt (2009) quando, pautada no modelo "rizomático" de Deleuze e Guatari (1996), aponta a riqueza múltipla que se encontra no panteão afro-cubano e quando categoriza Shango (orixá de origem yorubá/lucumí), Santa Bárbara (catolicismo) e a divindade chinocubana Sán Fakón como pertencentes ao mesmo panteão, mas não hierarquicamente. 


\section{Referências Bibliográficas}

AICARDI DE SAINT PAUL, Marc. La Chine et l'Afrique, entre engagement et interêt. Géopolitique Africaine, 2004, s/p. Disponivel em: <http://www.afriquechine.net/2004/la-chine-et-l'afriqueentre-engagement-et-interet.html>.

AJAKAYIE, Olu. China and Africa: Opportunitties and Challenges. Addis Ababa/Etiópia: African Economic Research Consortium (Aerc), 11-13 set. 2006. Disponível em: <http://dspace. africaportal.org/jspui/bitstream/123456789/32069/1/Opportunities_and_Challenges\%20_Olu. pdf?1>.

ALDEN, Chris. Red Star, Black Gold. Review of African Political Economy. London, v. 32, n. 104/105, p. 415-419, jun/set. 2005.

ROTHMAN, Andy. China and Africa: Special Report. CLSA Asia-Pacific Markets. Hong Kpng, p. 1-27, set. 2006.

DAVIES, Martyn. Chinese Multinational Corporations in Africa. China-Africa workshop. Hong Kong, p. 1-11, 11 - 12 nov. 2006. Disponivel em: http://www.cctr.ust.hk/materials/ conference/china-africa/papers/Chris_Alden_Chinese_Multinational_Corporations.pdf. Acessado em 20/11/2016.

AMSELLE, Jean-Loup. Branchements. Anthropologie de la universalité. Paris: Flammarion, 2001. $265 p$.

APPADURAI, Arjun. The social life of things. Commodities in cultural perspective. United Kingdom: Cambridge University Press, 1986. 339p.

The Globalization of Archaeology and Heritage: A discussion with Arjun Appadurai. .Journal of Social Archaeology, n. 1, p. 35-49, jun. 2001.

BALANDIER, Georges. Sociologie actuelle de I'Afrique Noire. Changements sociaux au Gabon et au Congo. Archives de Sociologie des Religions, n. 1, p. 191-192, 1956.

BHABHA, Homi. The location of culture. London and New York: Routledge. 2004 [1994]. 440p.

BOCKIE, Simon. Death and the invisible powers: The World of Kongo belief. Bloomington: Indiana University Press, 1993. 176p.

BOYER, Véronique. Le don et l'initiation: De l'impact de la littérature sur les cultes de possession au Brésil. L'Homme, v. 36, n. 138, p. 7-24, 1996.

BRASIO, António, padre. Monumenta missionaria africana. África ocidental. Lisboa: Agencia Geral do Ultramar, Divisão de Publicações e Biblioteca, 1952-1954.

BRÄUTIGAM, Deborah. Chinese Aid and African Development: Exporting Green Revolution. New York: St. Martin's Press, 1998. 268p.

BUKUASA, Tulu Kia Mpansu. L'impensé du discours. Kindoki et nkisi en pays kongo du Zaïre, Kinshasa: Presses Universitaires du Zaïre, 1973. 321p.

CANNELL, Fenella. The Christianity of Anthropology. The Journal of the Royal Anthropological 
Institute, v.11, n. 2, p. 335-356, 2005.

CARAYANNIS Tatiana; NATHANIEL, Olin. Practices without evidence: interrogating conflict resolution approaches and assumptions. JSRP, paper 11, Justice and Security Research Programme. LSE, Feb. 2014. 44p. Disponível em: <http://www.lse.ac.uk/internationalDevelopment/research/ JSRP/downloads/JSRP11.CarayannisEtAl.pdf>. Acesso em 29/11/2016.

CARRITHERS, Michael et al. Is Anthropology art or science? Current Anthropology, v. 31, n. 3, p. 263-82, 1990.

CHANG, Sen-Dou. The distribution and occupations of overseas Chinese. Geographical Review, 58 (1), p. 89-107, 1968.

COMMAROFF. John; COMMAROFF, Jean. Ethnography and the Historical Imagination. Westview Press, 1992. 352p.

CSORDAS, Thomas. Language, Charisma, and Creativity: The Ritual Life of a Religious Movement. Berkeley; Los Angeles; Londres: University of California Press, 1997. 320p.

CUNHA Ana Stela; NDUNGl, José Maria Masanga. Mizulas, chineses e mortos: reconfigurações religiosas no Baixo Congo. Revista eletrônica BUALA. Fev. 2013. Disponível em: <http://www. buala.org/pt/a-ler/mizulas-chineses-e-mortos-reconfiguracoes-religiosas-no-baixo-congo>. Acessado em 23/12/2016.

DELEUZE, Guilles; GUATARI, Felix. Mil Platôs: capitalismo e esquizofrenia. Rio de Janeiro: Editora 34, 1996. 715p.

DE BOECK, Filip. Post colinialism: Power and Identity. Local and Global Prespectives from Zaire. In: WERBENER, Richard; RANGER, Terrence (eds.). Post colonial Identities in Africa. London: Zed Books Ltd, p. 96-106, 1996.

EWING, Katherine. The dream of spiritual initiation and the organization of self-representations among Pakistani Sufis. The American Ethnologist Journal, v. 17, n. 1, p. 56-74, fev. 1990.

FANON, Franz. Toward the African Revolution. Political Essays. New York: Ed. Groove Press, 1967. $197 \mathrm{p}$.

FELNER, Albuquerque. Angola: apontamentos sobre a ocupação e início do estabelecimento dos portugueses no Congo, Angola e Benguela extraídos de documentos históricos. Coimbra, Imprensa da Universidade de Coimbra, 1993. 593p.

GOLDMAN, Marcio. Introdução: Políticas e subjetividades nos novos movimentos culturais. ILHA, Revista de Antropologia. Florianópolis, 9 (1), p. 8- 22, 2009.

HEWITT, Julia C. Voices out of Africa in Twentieth-century Spanish Caribbean Literature. S/l: Bucknell University Press, 2009. 402p.

JADIN, Louis. Le Congo et la secte des Antoniens: Restauration du Royaume sous Pedro IVet la «Saint Antoine» congolaise: 1694-1718. Bulletin de L'Institut Historique Belge de Rome, 33, p. 411-615, 1965.

JANZEN, John M. The Quest for Therapy in Lower Zaire. Berkeley, California: University of California Press, 1978. 266p.

MAKOUTA-MBOUKOU, Jean-Pierre. Les exilés de la forêt vierge, ou le grand complot. Paris: Ed. 
Harmattan, 1981. 206p.

MA MUNG, Emmanuel. Chinese Migration and China's Foreign Policy in Africa. Journal of Chinese Overseas, v. 4, n. 1, p. 91-109, maio 2008.

MAHANIAH, Kipianga. La mort dans la pensée Kongo. Kinshasa, Zaire: Centre de vulgarisation agricole, 1980. 57p.

MFUKA, Simon. The concept of the death and its impact among Kongo-Manianga people of Lower Zaire. Dissertação (Mestrado em Teologia). Graduate Theological Union, 1981. 187p.

MULEMFO, M. M. Traditional and the Christian concepts of disease and healing among the Manianga. HTS Theological Studies, vol. 51, no 2, p. 338-357, 1995.

OLIVEIRA, Roberto Cardoso de. O movimento dos conceitos na Antropologia. Revista de Antropologia, São Paulo, USP, v. 36, p. 13-31, 1993.

ROBBINS, Joel. Becomming Sinners: Christianity and moral torment in a Papua New Guinea society. Berkeley: University of California Press, 2004. 410p.

SAAVEDRA, Martha; STRAUS, Julia (Eds.). China and Africa: Emerging Patterns in Globalization and Development. Vol. 9. Cambridge: Cambridge University Press, 2009. 251p.

SARRÓ, Ramón. The Politics of Religious Change on the Upper Guinea Coast: Iconoclasm Done and Undone. Edinburgo: Edinburgh University Press, 2008. 238p.

SAUTMAN, Barry. Trade, Investment, Power and the China in Africa Discourse. The Asia Pacific Journal, Vol. 7, Issue 52, n. 3, p. 9-29, 2006. Disponível em: <http://apjif.org/-Barry-Sautman/3278/ article.html>.

SENGHOR, Léopold. Poemas. Lisboa: Ed. Arcádia, 1977. 260p.

SILVA, Orlando Sampaio; LUZ, Lídia; HELM, Cecília Maria Viera (Orgs.). A perícia antropológica em processos judiciais. Florianópolis: Editora da UFSC, 1994. 146p.

THORNTON, John K. Early Kongo-Portuguese Relations: A New Interpretation. History in Africa, v. 8, p. 183-204, 1981.

Africa and Africans in the making of the Atlantic World: 1400 - 1800. Cambridge: Cambridge University Press, 1998. 340p.

Warfare in Atlantic Africa. London: University College London (UCL) Press, 2002. 194p.

Cannibals, witches, and slave traders in the Atlantic world. William and Mary Quarterly, Omohundro Institute of Early American History and Culture, v. 60, n. 2, p. 273-94, abr. 2003.

Afro-Christian Syncretism in the Kingdom of Kongo. The Journal of African History, v. 54, n. 1, p. 53-77, mar. 2013.

The Kingdom of Kongo and Palo Mayombe: Reflections on an African-American Religion. Slavery and Abolition, v. 37, n. 1, p, 1-22, 2015.

VAN DIJK, Teun A. Elite discourse and racism. Thousands OAKS, CA: Sage, 2000. 320p. 
VANSINA, Jan. How Societies Are Born: Governance in West Central Africa Before 1600. Charlottesville, Virginia: University of Virginia Press, 2004. 320p.

VILAÇA, Aparecida. Conversão, predação e perspectiva. Mana. Estudos de Antropologia Social, v. 14, n. 1, p. 173-204, abr. 2008.

VITEBSKY, Peter. From Cosmology to Environmetalism: Shaman as local knowlodge in a global setting. In: FARDON, Richard (ed.). Counterworks mananging the diversity of knowlodge. London, Routledge, p. 182-203, 1995.

XIANG, Biao; PIEKE, Frank. Legality and Labour: Chinese Migration, Neoliberalism and the State in the UK and China. British Inter-University China Centre, University of Oxford, Working Papers Series, no 5, 2007. 36p.

YOUNG, Davi; GAULET, Jean-Guy. Being changed by cross-cultural encounters: the anthropology of extraordinary experience. University of Toronto Press, 1994. 384p.

ZAMENGA, Batukezanga. Milles kilometres a pied. Kinshasa, Éditions Saint Paul, 1985. 102p.

Recebido em: 26 de outubro de 2016.

Aprovado em: 11 de novembro de 2016. 